\title{
A FILOSOFIA ENQUANTO EXPERIÊNCIA DO PENSAR NO ENSINO MÉDIO: O PROCESSO DE ENSINO E APRENDIZAGEM NO DISCURSO FI- LOSÓFICO DA SÉRIE DE TELEVISÃO MERLÍ
}

\author{
PHILOSOPHY AS EXPERIENCE OF THINKING IN HIGH SCHOOL: THE PROCESS OF \\ TEACHING AND LEARNING IN THE PHILOSOPHICAL DISCOURSE OF THE MERLÍ \\ TELEVISION SERIES
}

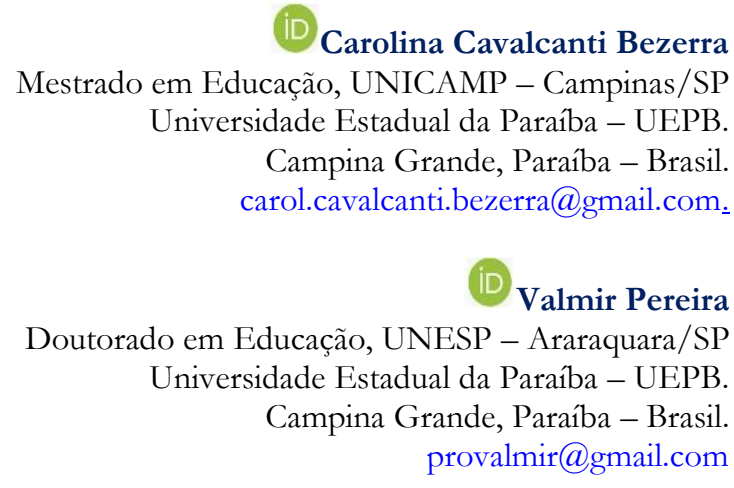

Resumo: Não apenas o cinema, mas também a televisão, reforçam a importância das imagens agentes na formação acadêmica inicial de crianças e jovens inseridos em um mundo cercado por personagens que ditam o nosso dia a dia imaginário. A leitura a seguir apresenta a série de TV Merlí, que suscita discussões acerca da desvalorização do ensino de filosofia, em especial no Brasil, que são corroboradas pelas políticas públicas mais recentes instituídas que reforçam a negligência do Estado brasileiro com o saber e fazer pensar de nossos estudantes. Por outro lado, a arte e o seu uso didático pedagógico dão esperança para o fazer, ensinar e refletir, assim como para as discussões e construções reflexivo acadêmicas sobre a Filosofia e o ato de filosofar.

Palavras-chave: ensino de filosofia; televisão; discurso filosófico; Merlí.

Abstract: Not only the cinema, but also the television, reinforce the importance of the agent images in the initial academic formation of children and young people inserted in a world surrounded by characters that dictate our imaginary daily life. The following reading presents the TV series Merlí, which raises discussions about the devaluation of the teaching of philosophy, especially in Brazil, which are corroborated by the most recent public policies instituted that reinforce the neglect of the Brazilian State with the knowledge and thinking of our students. On the other hand, art and its didactic pedagogical use give hope for doing, teaching and reflecting, as well as for discussions and academic reflective constructions about Philosophy and the act of philosophizing.

Keywords: philosophy teaching; television; philosophical discourse; Merlí.

\section{Para citar - ABNT NBR 6023:2018}

BEZERRA, Carolina Cavalcanti; PEREIRA, Valmir. A filosofia enquanto experiência do pensar no ensino médio: o processo de ensino e aprendizagem no discurso filosófico da série de televisão Merlí. Cadernos de Pós-graduação, São Paulo, v. 20, n. 1, p. 6576, jan./jun. 2021. Disponível em: https://doi.org/10.5585/cpg.v20n1.19636. 
Introdução

Há alguns anos presenciamos o desmonte do ensino de filosofia nos bancos escolares e as inúmeras tentativas de resgatá-lo por meio de reformas na Educação nacional. Historicamente, desde a chegada dos jesuítas ao Brasil, quando seu oferecimento estava restrito a um grupo privilegiado de pessoas (de classes mais abastadas ou de religiosos), a filosofia vem sendo tratada de forma subliminar e aquém de suas potencialidades. Seu ensino já esteve vinculado a questões teológicas, a movimentos políticos (como o fim da Ditadura no país) e mais exponencialmente à reprodução de um ensino não crítico e não reflexivo.

Entretanto, a filosofia está para "o uso do saber em proveito do homem” e nas suas várias compreensões ao longo de determinados momentos históricos onde "de nada serviria uma ciência que tornasse imortal a quem não soubesse utilizar a imortalidade, e assim por diante" (ABBAGNANO, 2012, p. 514).

Quando das mudanças políticas no âmbito federal, que podem ocorrer de quatro em quatro anos, elegendo ou não sucessores e mantendo ou não políticas públicas na área da educação, o ensino de filosofia ora ressurge como obrigatório, ora é relegado aos estudos optativos, transversais ou complementares a outros componentes curriculares. Atualmente, com a nova legislação que a oferece no Ensino Médio, seu ensino foi reduzido a uma aula por semana.

Por esta razão, este artigo visa contribuir para a construção de produção científico-acadêmica sobre a filosofia no ensino médio, reiterando sua historicização desde sua chegada, manutenção/exclusão e sua importância no campo da formação do conhecimento humano no Brasil, a partir de uma reflexão crítica de seus saberes inserida nas práticas curriculares.

Com esse intuito, nos propomos a pensar a filosofia nas suas dimensões política e pedagógica na busca pela construção de sujeitos históricos, sociais e envolvidos com a coletividade. E, para isso,submetemos vislumbrar o ensino de filosofia tomando como um dos esteios, uma prática curricular muito exitosa entre os jovens, o uso do audiovisual; não apenas como uma complementaridade aos estudos, mas como um resgate da importância da Filosofia nos bancos escolares para o ato de filosofar, ou seja, de se ter uma visão própria do mundo a partir da crítica e da reflexão, como diria Gramsci (1995).

Para tal empreitada, escolhemos a série de televisão Merlí como nosso aporte e suporte para as proposituras a serem apresentadas. Vejamos do que se trata, brevemente, a atração televisiva. Entre os anos de 2015 e 2018 um canal de televisão da Catalunha, região autônoma da Espanha formada pelas províncias de Barcelona, Girona, Lérida e Tarragona, produziu a série de televisão Merli, que tem como protagonista um professor de Filosofia, que dá nome a série. 
Durante três temporadas e quarenta episódios o ensino de filosofia se misturou aos ensinamentos sobre a vida, proporcionados pelos diálogos filosóficos e pela proximidade construída pelo professor com seus estudantes. Da antiguidade até à contemporaneidade, Merlí burla o sistema e se vale de métodos pedagógicos pouco convencionais e transforma uma sala de aula do ensino médio, desperta o interesse dos seus alunos pela reflexão sobre o cotidiano - o pensamento filosófico, e isso provoca mudanças expressivas nos seus alunos.

A partir da série Merlí e dos procedimentos pouco normatizados do professor dentro e fora da sala de aula, apresentaremos como a construção imagética e dialógica se dá em um episódio específico - o que tratará de Karl Marx, a partir de um roteiro escrito para discutir os assuntos filosóficos em comunhão com os desafios da vida adolescente, e preparar uma turma do ensino médio para o diálogo crítico, tendo o ato de refletir como esteio do saber e do pensamento. Mas, antes disso, precisamos recordar o lugar da Filosofia na Educação brasileira.

\section{$2 \mathrm{O}$ ensino de filosofia no Brasil: pinceladas}

Para valorizar o ensino de filosofia em nossas escolas, as mesmas devem dar condições para uma formação cidadã, física, cognitiva e socioemocional voltada para o protagonismo do jovem (BRASIL, 2018). É neste contexto que, para nós, se insere o professor de Filosofia.

Podemos constatar, novamente, uma convergência entre o papel educador da Filosofia e a educação para a cidadania [...]. Os conhecimentos necessários à cidadania, à medida que se traduzem em competências, não coincidem, necessariamente, com conteúdos, digamos, de ética e de filosofia política. (BRASIL, 2006, p. 31).

O excerto extraído das Orientações Curriculares para o Ensino Médio (2006) reforça a ideia inicial proposta pelo título deste artigo "A filosofia enquanto experiência do pensar no ensino médio" e que se justifica na busca por um ensino de filosofia e pelo ato de filosofar que

\footnotetext{
[...] é a contribuição mais importante da Filosofia: fazer o estudante aceder a uma competência discursivo-filosófica. [...] Com isso, a possibilidade de tomar posição por sim ou por não, de concordar ou não com os propósitos do texto é um pressuposto necessário e decisivo para o exercício da autonomia e, por conseguinte, da cidadania. (BRASIL, 2006, p. 30-31, grifo nosso).
}

Por outro lado, a Base Nacional Comum Curricular (BRASIL, 2018), bem como as mais recentes discussões sobre a criação de áreas do conhecimento norteadoras do processo de ensino e aprendizagem, como a de Linguagens, Códigos e suas Tecnologias (BRASIL, 2006), reforçam a importância da discussão de uma base curricular comum "como lugar de negociação, embates e disputas, sobre os sentidos padronizados ou não do currículo" (CUNHA; SILVA, 2016, p. 1239) e que devem propor consenso na construção de saberes, visando o 
[...] aprofundamento de conhecimentos estruturantes para aplicação de diferentes linguagens em contextos sociais e de trabalho, estruturando arranjos curriculares que permitam estudos em línguas vernáculas, estrangeiras, clássicas e indígenas, Língua Brasileira de Sinais (LIBRAS), das artes, design, linguagens digitais, corporeidade, artes cênicas, roteiros, produções literárias, dentre outros, considerando o contexto local e as possibilidades de oferta pelos sistemas de ensino. (BRASIL, 2018, p. 6, grifo nosso).

Mas, não uma padronização, pois os sujeitos

[...] que encontramos presentes nos discursos produzidos pelas articulações políticas que constituem a base das políticas curriculares, nas quais os saberes homogeneizados servem para formar sujeitos únicos, universais, como se todos fossem um no caminho das exigências de forças externas. (CUNHA; SILVA, 2016, p. 1240).

Ou seja, uma base curricular deve destacar as multiplicidade e heterogeneidade sociais, culturais e de identidades que o ensino médio engloba e "necessária para uma política de currículo que precisa ser também uma política cultural”. (CUNHA; SILVA, 2016, p. 1240).

Não podemos esquecer do vai e vem de redações com inclusão e exclusão de pontos relevantes nos mais diversos documentos legais. Ao traçarmos uma cronologia do ensino de filosofia, entre os anos de 1838 e 1878 com a ascensão de cursos profissionalizantes (para o mundo do trabalho) e superiores (formação acadêmica), o Ensino Médio tinha como objetivo encaminhar os alunos para um dos dois espaços. O ensino de filosofia se fazia presente, mas com uma série de limitações que iam desde o conteúdo a ser ministrado, o período em que deveria ser alocado e sua carga horária (GALLINA, 2000).

Com a Proclamação da República em 1889, a Filosofia perde seu espaço. Em 1915, é aprovada a Lei 11.530 que restringe a educação no Ensino Médio a um caráter preparatório, passando a ser facultativo o ensino de filosofia. No ano de 1925 é assinado o Decreto de no 16.782 (revogado posteriormente) que retoma a sua obrigatoriedade com aulas semanais no $5^{\circ}$ ano ( 3 aulas) do ensino secundário, visando uma formação do aluno para à vida em sociedade. Porém, no final da mesma década retomou-se a defesa pelo ensino religioso voltado para uma consciência de nacionalidade, no lugar do ensino de filosofia (GALLINA, 2000).

Com a redação da primeira Lei de Diretrizes e Bases da Educação em 1961 - Lei no 4.024 - "a educação de grau médio, em prosseguimento à ministrada na escola primária, destina-se à formação de adolescentes" (BRASIL, 1961), sendo vista como preparatória para a entrada no ensino superior, mas a Filosofia deixa de ser obrigatória e torna-se complementar.

No ano de 1972, por meio do Parecer n 5.692 do Conselho Federal de Educação, a Filosofia deixa de ser complementar e torna-se facultativa. Com a redação da nova Lei de Diretrizes e Bases da Educação Nacional no ano de 1996 - Lei 9.394 (BRASIL, 1996) - a Filosofia permanece fora do quadro oficial do currículo do Ensino Médio. 
Anos mais tarde, na redação das Diretrizes Curriculares Nacionais da Educação Básica (2013, p. 187) constam como componentes curriculares obrigatórios "VI - a Filosofia e a Sociologia em todos os anos do curso", referendadas pela Lei no $11.684 / 2008$ e pela Lei no $13.415 / 2017$ (BRASIL, 2008, 2017).

Entretanto, o atual momento da Educação, que tem na Resolução no 3, de 21 de novembro de 2018 as novas Diretrizes Curriculares Nacionais para o Ensino Médio, tornaram apenas obrigatórias em todos os anos do ensino médio os componentes curriculares de Matemática e Língua Portuguesa.

$\int 7^{\circ}$ A critério dos sistemas de ensino, a formação geral básica pode ser contemplada em todos ou em parte dos anos do curso do ensino médio, com exceção dos estudos de língua portuguesa e da matemática que devem ser incluídos em todos os anos escolares (BRASIL, 2018, p. 6).

Sobre a perda que é para a formação dos jovens a não obrigatoriedade do ensino de filosofia, Guido nos faz refletir quando pondera que:

A negligência consciente para o ensino de filosofia perpetua as deficiências do ensino escolar, mantendo-os presos - na quase totalidade do universo escolar - a um currículo estático e composto por disciplinas acabadas, sem perspectiva de progresso. Quando o pensamento dominante nas escolas é este, os conhecimentos de filosofia terão o mesmo destino e, nessa direção, não há filosofia e tampouco a sua prática: o filosofar. (GUIDO, 2000, p. 87).

O trecho reflete bem o atual momento da educação no Brasil, bem como o atraso e estagnação de nosso sistema de ensino, refletido e muito na prática docente do professor de Filosofia.

3 Merlí e os peripatéticos: práticas curriculares, espectadores, consumidores e a filosofia da linguagem

Merlí é um homem com mais de 50 anos, fracassado profissionalmente, que ao ser despejado de seu apartamento precisa voltar a morar com sua mãe. Sua relação com o filho também é estreitada, mesmo que de forma forçosa, quando o mesmo é deixado por sua ex-mulher sob sua custódia. Se suas relações familiares parecem conturbadas, a conquista da vaga de professor substituto de Filosofia no Instituto Àngel Guiméra lhe traz novas motivações: ser o melhor professor de Filosofia se valendo dos seus próprios métodos de ensino e conquistar a vaga definitiva na instituição ${ }^{1}$.

\footnotetext{
${ }^{1}$ A série tem uma característica importante: é falada em catalão e não em castelhano. O uso de uma língua que não a oficial do país é por si só um ato político, de contestação e de enfrentamento em um momento político espanhol conturbado; junte-se a isso, a escolha da Filosofia e da reflexão sobre a independência da Catalunha aparecer em determinados episódios, outro motivo de destaque que reforça a importância da atração que vai muito além do entretenimento. Vale lembrar que no ano de 2017, houve um referendo com posterior declaração de independência da República Catalã da Espanha. Não houve reconhecimento de nenhuma nação do Estado da Catalunha, o que gerou vários conflitos políticos naquele ano e em anos seguintes.
} 
Merlí, em um dos episódios de suas três temporadas, apresenta o filósofo alemão Karl Marx (1818-1883) aos seus peripatéticos². Alguns conceitos são discutidos a partir do sumiço de um laptop. Merlí não tinha um plano de aula estabelecido, mas pode falar de sociedade capitalista, fetichismo do mercado, sistema, consumo, dinheiro, produção, roubo, propriedade privada e alienação ${ }^{3}$.

Vão se desenrolando discussões acerca do consumo desenfreado e a importância que se dá às aparências em uma sociedade consumista, enquanto se tenta descobrir quem roubou o laptop de um aluno. O marxismo, a trama do episódio, e um acontecimento específico levantaram um debate acalorado sobre o mundo atual. O surgimento de regras que instituíram a propriedade privada e a classificação do roubo fizeram os alunos refletirem sobre o certo e o errado, ao mesmo tempo em que os diálogos mexiam com a consciência de cada um, de maneiras distintas, em uma sala de aula de escola pública. Quem teria pego o laptop teve sua ação justificada pelas explanações de Merlí a partir do pensamento marxista?

O episódio que tratou dos conceitos cunhados por Marx é apenas um dos muitos momentos de debate em sala de aula que se valem de teorias exemplificadas ou comparadas com fatos do cotidiano, da realidade dos alunos e da classe social a qual fazem parte.

A imagem de Marx em uma revista é apresentada aos alunos, que ao tentarem absorver toda a informação passada pelo professor de forma esfuziante, também se surpreendem com a figura de um senhor barbudo responsável por tantos conceitos cunhados em séculos anteriores e que hoje se encontram tão presentes em seus cotidianos, dos mais ricos (o dono do laptop) até dos mais pobres (um dos suspeitos do furto da "madeira/objeto" tecnológico). Este fazer educativo, que tem na figura do professor seu maior expoente, nos interessa na medida exata em que há um diálogo com a contemporaneidade que desperta o interesse dos estudantestorna o aprendizado mais prazeroso através dos embates filosóficos, disputatio ${ }^{4}$. Assim como o uso do audiovisual ${ }^{5}$.

Abrir portas para uma nova leitura do uso do audiovisual voltado para o ensino de filosofia, proporcionando novas experiências e leituras ao saber e fazer docente deve buscar o protagonismo para o ensino de filosofia enquanto prática de reflexão. Nos parece primordial à análise: uma "educação filosófica" para à prática de filosofar do discente no ensino médio. A televisão,

\footnotetext{
2 Aqueles que seguiam Aristóteles, suas doutrinas e em suas caminhadas filosóficas, eram conhecidos como peripatéticos (ABBAGNANO, 2012).

${ }^{3}$ Boa parte desses conceitos são discutidos no livro Os Despossuídos: debates sobre a lei referente ao furto da madeira, que em 2017 teve uma edição publicada pela Editora Boitempo.

${ }^{4} \mathrm{Na}$ Idade Média era muito comum debates entre os alunos, como forma de aprendizado. Eram batalhas saudáveis em que duas ou mais pessoas defendiam seus pontos de vista sobre alguma temática específica.

${ }^{5}$ Reforçando a importância da metodologia do uso do audiovisual na prática docente, em 2019, o filósofo e professor Renato Janine Ribeiro ofereceu o curso de extensão 'Merlí e o Ensino Médio'. Com nove encontros que foram gravados e posteriormente disponibilizados pela instituição, o curso foi oferecido para estudantes de graduação, mas também para professores do ensino médio da rede pública de ensino de São Paulo.
} 
assim com o cinema, são as grandes ferramentas para a "popularização" da Filosofia e do prazer de filosofar.

Conforme aponta Matín-Barbero (2002), o consumo de audiovisual nos possibilita o contato com culturas e valores das mais diversas origens, que sendo analisados e até comparados podem trazer novos olhares para a nossa própria cultura escolar.

A existência de uma distinção entre ser um simples consumidor e ser um cidadão com capacidade de compreensão e julgamento das imagens produzidas e ora vendidas como simples produtos do entretenimento pode nos definir como meros espectadores/consumidores; ou podemos fazer das horas de lazer em frente à televisão, também, momentos de aprendizagem (CANCLINI, 2008).

Não há como não lembrar das discussões pioneiras de Paulo Freire e suas análises e escritos que interligam o processo de comunicar (interação) ao processo de educação, onde o comunicar constrói o saber através de "sujeitos interlocutores que buscam a construção dos significados" (AZEVEDO, 2005, p. 67).

Freire (1983, p. 45) destaca que a importância dos agentes no processo comunicativo deve ser participativa e, completa afirmando que "a expressão verbal de um dos sujeitos tem que ser percebida dentro de um quadro significativo comum ao outro sujeito".

Ao olharmos o ensino de filosofia a partir de uma série de TV, onde de um lado estão produtores, direção, atores e de outro nós, os consumidores, o aprofundamento teórico volta-se para ferramentas e processos de comunicação. E, tendo em vista que "toda comunicação - enquanto produção simbólica e intercâmbio/transmissão de sentidos é, em si, uma 'ação educativa' " (SOARES, 2011, p. 17), a evolução tecnológica e a variedade de meios de comunicação, assim como as transformações na forma de consumo de produtos audiovisuais e claramente de seus consumidores, reforçam que

[...] existe um jogo complexo, em várias direções, entre ser cidadão e ser consumidor. Em algumas formas de expansão e consumo, como Internet, ou com o aumento da escolaridade média e superior, criam-se melhores condições para que nós, consumidores, sejamos capazes de apreciar repertórios culturais e estéticos diversos. (CANCLINI, 2008, p. 28).

Canclini aponta, com relevância em sua fala, como as novas formas de acesso aos bens culturais vêm se dando ao longo dos anos: 
As fusões multimidia e as concentracõoes de empresas na produção de cultura, correspondem, no consumo cultural, à integração de rádio, televisão, música, notícias, livros, revistas e Internet. Devido à convergência digital desses meios, são reorganizados os modos de acesso aos bens culturais e às formas de comunicação. Parece mais fácil aceitar o processo socioeconômico das fusões do que reconsiderar o que vinha sendo sustentado nos estudos sobre educação e leitura nas políticas educacionais, culturais e de comunicação. (CLANCLINI, 2008, p. 33)

Com a evolução tecnológica cada vez mais rotineira, as grandes empresas de comunicação foram se transformando em grandes monopólios, com fusões entre companhias de comunicação e entretenimento tradicionais com as de serviços de comunicação pela internet.

Fischer (2003, p. 15) pesquisa sobre a televisão "na sua íntima relação com a produção de modos de subjetivação na cultura" e que nos interessa na exata medida em que programas de televisão podem contribuir para a construção de sujeitos e a reprodução de significados, no que tange o objeto de nossa leitura, a Filosofia e seu ensino. Para o autor,

[...] todo esse complexo aparato cultural e econômico — de produção, veiculação e consumo de imagens e sons, informação, publicidade e divertimento, com uma linguagem própria - é parte integrante e fundamental de processos de produção e circulação de significações e sentidos, os quais por sua vez estão relacionados a modos de ser, a modos de pensar, a modos de conhecer o mundo, de se relacionar com a vida. (FISCHER, 2003, p. 15).

Destarte, para dialogar com o que até aqui foi apresentado, nos apropriamos da Filosofia da Linguagem, através do Círculo de Bakhtin e do filósofo russo Mikhail Bakhtin (1895-1975), para quem a filosofia está na linguagem. Tendo alguns dos seus estudos como fonte, nos cercamos de algumas de suas conceituações, pois nos parece possível tal diálogo com os propostos anteriormente e que tratam dos processos comunicativos. ${ }^{6}$

Para o Círculo de Bakhtin, os significados e significações caracterizam objetos em suas relações com os indivíduos na sociedade e a palavra materializa a linguagem a partir de uma enunciação única, que significa uma realidade.

Para Bakthin (2006, 2003), isto ocorre quando há uma significação social fruto das relações culturais e que trará à tona uma simbologia de valores (axiologia) (SOUZA, DI CAMARGO JR., LOURENÇO, MORETTTO, 2020).

O diálogo com Bakhtin reforça a ideia de que as aulas de Merlí - discursos roteirizados com uma intencionalidade - tensionam os estudantes (sujeitos) à reflexão, ao embate de vozes, ao diálogo entre discursos - históricos e sociais preexistentes - reforçando que "o dialogismo é uma interação entre visões de mundo, assim formando a relação entre os enunciados" (SOUZA et. al., 2020, p. 16).

\footnotetext{
${ }^{6}$ Conceitos do filósofo como "dialogismo", "alteridade", "polifonia" e "axiologia" podem trazem algumas leituras interessantes e que dialogam positivamente com as proposituras deste artigo. Os termos podem ser melhor conhecidos nos textos usados como aporte acadêmico para este artigo e disponibilizados nas referências, ou na vasta obra do autor.
} 
Para o filósofo, “[...] o objeto real é o homem social (inserido na sociedade), que fala e exprime a si mesmo por outros meios (BAKHTIN, 2003, p. 319). Aqui, o "homem social", nosso “sujeito", está no professor de ensino médio, ideológico e com um discurso constituído, mas também nos estudantes que fazem parte do dialogismo e da polifonia do processo de ensino e aprendizagem, por que não, proposto pela série Merlí.

Foucault (2002, p. 9) afirma que os discursos são “jogos estratégicos de ação e reação, de pergunta e de resposta, de dominação e de esquiva, como também de luta. O discurso é um conjunto regular de fatos linguísticos em determinado nível, e polêmicos e estratégicos em outros”, complementa.

A enunciação e a concepção dialógica da linguagem reforça a presença do Outro (alteridade) na concepção dos sentidos no discurso, estando locutor e interlocutor presentes no processo de significação.

\footnotetext{
Na realidade, toda palavra comporta duas faces. Ela é determinada tanto pelo fato de que procede de alguém, como pelo fato de que se dirige para alguém. Ela constitui juntamente o produto da interação entre locutor e ouvinte. Toda palavra serve de expressão a um em relação ao outro. Através da palavra, defino-me em relação ao outro, isto é, em última análise em relação à coletividade. [...] A palavra é o território comum do locutor e do interlocutor. (BAKHTIN, 2006, p. 115).
}

Sendo assim, tendo apresentado os pormenores desse estudo iniciado na graduação, estendido a congressos e grupos de pesquisa dentro da universidade, que pautou a política pública nacional para o ensino de filosofia, uma série de televisão catalã e práticas pedagógicas e comunicativas, vislumbramos alguns apontamos a seguir.

\section{Algumas considerações}

Encontrar um consenso, favorável, sobre o ensino e aprendizagem da Filosofia não somente na escola pública, mas também na atual conjuntura política do país onde a Educação de qualidade, de livre expressão, cada vez mais vem sendo ameaçada, é um desafio. O ato de refletir, o filosofar mediante tantos contratempos não tem sido tarefa fácil de se ensinar.

Salles (2016) nos aponta um direcionamento sobre a formação da prática filosófica no ensino médio nos dias atuais e que reforça

[...] a clara importância da investigação filosófica na vida e nas práticas escolares dos alunos, como dispositivo e recurso de formação, em que a experiência de reflexão se faz, ela mesma, experiência prática. Nesse processo, por assim dizer formativo-filosófico, o modo de ser, de aprender e de ensinar já não é definido a priori, mas é imanência, possibilidade que se instaura e se inscreve na experiência. (SALLES, 2016, p. 83). 
Especificamente neste texto, a autora faz uma contextualização do surgimento da Filosofia, que de herança tomista e positivista no século XVI ganha um caráter um pouco mais moderno no início do século XIX com o surgimento, no Brasil, das faculdades de Direito e Medicina, e mais cientificista no século XX, com a influência de filosofias norte-americanas e o pensamento marxista.

Para a autora, deve-se ir "além do ensino da história da filosofia, de habilidades de pensamento e de temas ou questões” (SALLES, 2016, p. 79). O ensino de filosofia deve se constituir de uma "experiência do pensar" e não do "raciocinar" "calcular" "argumentar" (CERLETTI, 2004; KOHAN, 2000 apud SALLES, 2016, p. 80).

Ainda sobre essa questão, Salles complementa afirmando que

Partimos do princípio que a experiência do pensar filosófico implica uma aposta ao ensino e aprendizado de quem nela está envolvido, e não na sua renúncia, como estabelecem, de saída, alguns vínculos pedagógicos, ao imporem processos de aprendizagem pouco permeados pela problematização e criação. (SALLES, 2016, p. 81)

Sendo assim, e tendo problematizado a importância do pensar a filosofia no ensino médio a partir de algumas fontes acadêmicas, que englobam desde políticas públicas para o ensino de filosofia no Ensino Médio, saberes e formação de professores, processos comunicativos e a filosofia da linguagem como norteadores e entendendo que tivemos "como principal meta refletir os sujeitos sobre os processos de experimentação do real, do virtual e de si mesmo" (SOUZA, 2007, p. 90), a partir do episódio Karl Marx, da série de tevê Merlí, os discursos aqui oferecidos são metodologias pertinentes na formação escolar (em qualquer nível).

Ou seja, aquele discurso oralizado da sala de aula discursivo-dialógico, do tentar trazer para perto de si alunos pouco interessados no ato de filosofar é a realidade dos bancos escolares, refletida na legislação vigente para o ensino de filosofia, no Brasil. Por outro lado, há uma tentativa latente de trazer a Filosofia para seu lugar de destaque na sociedade - mesmo que erroneamente quando a vincula a filosofias de vida - e que tem como suporte tecnológico imagens reproduzidas nas tevês ou em salas de cinema ou mais recentemente através das plataformas de streaming, como se verificou a partir do grande sucesso da série Merli em todo o mundo.

A Filosofia e o filosofar é um ato de resistência. Mais do que tudo, de sobrevivência nos dias atuais. A Filosofia, enquanto experiência do pensar no ensino médio, para a uma formação docente e discente, ganhou um grande aliado para o processo de ensino e aprendizagem, e este encontra-se no discurso filosófico-pedagógico da série de televisão Merlí. Um oásis para alunos e professores que podem vislumbrar, mesmo que ingenuamente a partir da tevê, o ressurgimento da liberdade do ato de pensar através de disputatios pedagógicos. 


\section{Referências}

AZEVÊDO, S. R. S. Gênero, rádio e educomunicação: caminhos entrelaçados. João Pessoa: Editora Universitária/UFPB, 2005.

ABBAGNANO, N. Dicionário de Filosofia. 6.ed. São Paulo: Editora: WMF Martins Fontes, 2012.

BAKHTIN, M. M. Estética da criação verbal. São Paulo: Martins Fontes: 2003.

BAKHTIN, M. M. Marxismo e Filosofia da Linguagem. 6.ed. São Paulo: Hucitec, 2006.

BRASIL. Ministério da Educação. Secretaria de Educação Básica. Secretaria de Educação Continuada, Alfabetização, Diversidade e Inclusão. Diretriz̧es Curriculares Nacionais Gerais da Educaşão Básica. Brasília: MEC, SEB, DICEI, 2013.

BRASIL. Lei n ${ }^{\circ}$ 4.024, de 20 de dezembro de 1961. Fixa as Diretrizes e Bases da Educação Nacional. 1961. Disponível em: http://www.planalto.gov.br/ccivil_03/leis/L4024.htm. Acesso em: 01 set. 2020.

BRASIL. Lei ñ 9.394, de 20 de dezembro de 1996. Estabelece as diretrizes e bases da educação nacional. 1996. Disponível em: http://www.planalto.gov.br/ccivil_03/leis/19394.htm. Acesso em: 01 set. 2020.

BRASIL. Ministério da Educação. Secretaria de Educação Básica. Ciências Humanas e suas Tecnologias. Orientações Curriculares para o Ensino Médio, volume 3. 2006. Disponível em: http://portal.mec.gov.br/seb/arquivos/pdf/book_volume_03_internet.pdf. Acesso em: 17 jul. 2020.

BRASIL. Lei $n^{\circ}$ 11.684, de 2 de junho de 2008. Altera o art. 36 da Lei no 9.394, de 20 de dezembro de 1996, que estabelece as diretrizes e bases da educação nacional, para incluir a Filosofia e a Sociologia como disciplinas obrigatórias nos currículos do ensino médio. 2008. Disponível em https://www2.camara.leg.br/legin/fed/lei/2008/lei-11684-2-junho-2008-575857-publicacaooriginal-99168-pl.html. Acesso em 24 ago. 2020.

BRASIL. Ministério da Educação. Linguagens, códigos e suas tecnologias: livro do estudante: ensino médio. 2013. Disponível em http://download.inep.gov.br/educacao_basica/encceja/material_estudo/livro_estudante/linguagens_codigos_em_br.pdf. Acesso em: 17 jul. 2020.

BRASIL. Ministério da Educação. Resolução nº 3, de 21 de novembro de 2018. Atualiza as Diretrizes Curriculares Nacionais para o Ensino Médio. 2018. Disponível em: https://www.in.gov.br/materia/-/asset_publisher/Kujrw0TZC2Mb/content/id/51281622. Acesso em 17 jul. 2020.

BRASIL. Ministério da Educação. Base Nacional Comum Curricular. 2018. Disponível em http://basenacionalcomum.mec.gov.br/images/BNCC_EI_EF_110518_versaofinal_site.pdf. Acesso em: 17 jul. 2020.

CANCLINI, N. G. Leitores, espectadores e internautas. São Paulo: Iluminuras, 2008.

CUNHA, K. S.; SILVA, J. P. Sobre base e bases curriculares, nacionais, comuns: de que currículo estamos falando? Revista e-Curriculum, São Paulo, v. 14, n.14, p. 1236-1257, out/dez, 2016. Disponível em: http://revistas.pucsp.br/curriculum/issue/view/1720. Acesso em: 25 mai. 2020. 
FISCHER, R. M. B. Televisão \& Educação: fruir e pensar a TV. 4.ed. Belo Horizonte: Autêntica Editora, 2013.

FISCHER, R. M. B. Televisão \& Educação: fruir e pensar a TV. 4.ed. Belo Horizonte: Autêntica Editora, 2013.

FOUCAULT, M. A verdade e as formas jurídicas. Rio de Janeiro: Editora Nau, 2002.

FREIRE, P. Extensão ou Comunicação? 7.ed. Rio de Janeiro: Paz e Terra, 1983.

GALLINA, S. F. S. A disciplina de filosofia e o ensino médio. In. GALLO, S.; KOHAN, W. O. (orgs.) Filosofia no Ensino Médio. 3.ed. Petrópolis: Vozes, 2000.

GRAMSCI, A. Concepşão dialética da bistória. 10.ed. Rio de Janeiro: Civilização Brasileira, 1995.

GUIDO, H. A. O. A filosofia no ensino médio: uma disciplina necesária. In. GALLO, S.; KOHAN, W. O. (orgs.) Filosofia no Ensino Médio. 3.ed. Petrópolis: Vozes, 2000.

MARTÍN-BARBERO, Jesús. La educación desde la comunicación. Enciclopédia Latinoamericana de Sociocultura y Comunicación. Buenos Aires: Grupo Editorial Norma, 2002.

MERLI. Direção: Eduard Cortés, Menna Fité. Produção: Héctor Lozano, Aitor Montánchez,Conxa Orea, Oriol Sala-Patau. Roteiro: Eduard Cortés. Intérpretes: Francesc Orella, CarlosCuevas, Carlota Olcina, Pere Ponde, Anna Maria Barbany, Martra Marco, Candela Antón,Albert Baró, Elisabet Casanovas. Espanha: Nova Veranda, Netflix, 2017. Série de TV em streming , colorido, idioma catalão, 58 minutos, sonoro, legendas em português.

SALLES, C. G. N. L. Da tradição filosófico-pedagógica aos caminhos da prática filosófica no ensino médio como experiência do pensar: ensinar filosofia ou filosofar? EccoS - Rev. Cient., São Paulo, n. 39, p. 71-84, jan./abr. 2016. Disponível em: https://periodicos.uninove.br/index.php?journal $=$ eccos\&page $=$ article\&op $=$ view\&path $\% 5 B \% 5 \mathrm{D}=6003$. Acesso em: 04 jul. 2020 .

SOARES, I. O. Educomunicação: o conceito, o profissional, a aplicação. Contribuições para a reforma do Ensino Médio. São Paulo: Paulinas, 2011.

SOUZA, S. J. Dialogismo e alteridade na utilização da imagem técnica em pesquisa acadêmica: questões éticas e metodológicas. In. FREITAS, M. T.; SOUZA, S. J.; KRAMER, S. Ciências Humanas e Pesquisa. Leituras de Mikhail Bakhtin. 2.ed. São Paulo: Cortez, 2007.

SOUZA, F. M.; DI CAMARGO JR.; I.; LOURENÇO, L. T. L.; MORETTO, M. (orgs.). Bakbtin dialogado: alteridade, relações dialógicas e sociedade. São Paulo: Mentes Abertas, 2020. 